\title{
“Organic Terrace” Android application
}

\author{
Dhanusha.T ${ }^{1}$, Dr. M. Kalpana Ph.D ${ }^{2}$ \\ Agricultural Information Technology Graduate, Tamil Nadu Agricultural University, Coimbatore, India ${ }^{1}$ \\ Assistant Professor, Tamil Nadu Agricultural University, Coimbatore, India ${ }^{2}$
}

\begin{abstract}
This paper expresses the idea about the creation of "Organic Terrace" an android application. Nowadays many people have smartphones, which everyone use in a resourceful manner. In recent trends, people upgrade their knowledge by mobile enabled information services. The growing trends in Agricultural Automation has led to a tremendous development of software and applications to foster and enhance the information dissemination. "OrganicTerrace"app helps the users by giving them information regarding organic methodof cultivation of vegetables and green leafy vegetables in their terrace. In this modern world, most of the people live in urban and sub urban areas. This application will be very much helpful for the people who are interested in cultivating their own vegetable cropsbut don't have a proper land area to cultivate them. The specialty of this application is to guide the users in the cultivation of crops in their terracewithout the use of any kind of synthetic (inorganic) fertilizers, pesticides, etc.
\end{abstract}

Keywords: Organic farming, Rooftop or terrace gardening, Android application, Expert advice, notifications.

\section{INTRODUCTION}

Android is the mostly used mobile operating system in the present world. Different kind of mobile applications are used by people for various purposes as they provide a more popular interface than using web applications via web browser.Androidoperating system has more users, more phones and more tablets worldwide than any other mobile operating system. The Google Play app store has been growing at breakneck speed.

Mobile applications provide substantial benefits for many people. With the development of android phones, the android applications have suddenly became an important aspect for local and global communications. The android system is very popular because of a major reason that they are open source and their development tools are free, so plenty of applications are generated[1].

This app "OrganicTerrace" is all about the rooftop cultivation of crops in an organic manner. It will guide the end users by givingthem necessary information about how to grow plants in the terrace or the rooftop of house. This application is more user friendly. The users can get expert advice through the app.

\section{REVIEW OF LITERATURE}

An android application whichhelps in delivering the crop specific fertilizer quantity to be applied. The idea of that app was to calculate the amount of NPK fertilizers to be applied based on the blanket recommendation of the crop of interest [2]. Each operating system has its own specialization. The applications differ from one operating system to the other. So the customer needs to use more than one mobile operating system to fulfill their requirements. They developed a mobile application for Multiplatform Operating Systems which will reduce the code development time and energy to half [3].Development of Fertilizer Apps (F Apps) is to develop a well informed Decision Making among the Farmers. The idea of this app is to calculate the amount of NPK fertilizers to be applied based on the blanket recommendation for the villages in Manikandam Block in Tiruchirappalli district [4]. AgriBot is a robot designed for agricultural purposes. As one of the trends of development on automation and intelligence of agricultural machinery in the 21st century, all kinds of agricultural robots have been researched and developed to implement a number of agricultural production in many countries. This Bot can perform basic elementary functions like picking, harvesting, weeding, pruning, planting, grafting [5].Flash Alert Notification System using Android project aims in developing an application for daily use having easy operation and easy to use. Usually when people are in meeting or any discussion where they have to put their mobile phones on silent mode on which their mobile phones don't even vibrate or else they are far from their mobile at that time [6].Agro Supply Chain will be an advisory and information system for the farmers. Agro Supply Chain will be available on mobile phones, which will be designed for farmers to help them stay on track, avoid troubles, manage their expenses in cultivation, receive all the latest and updated information, government schemes and strategies related to the field of agriculture along with suppliers details for sugarcane. The advisory system will enable its users to receive real-time and interactive advices and alerts on crop. Different alerts will be provided for plantation, insects, diseases and nutrition [7].Issues concerning agriculture have been always hindering the development of the country. The only solution to this problem is smart agriculture by modernizing the current 
traditional methods of agriculture. Hence the project aims at making agriculture smart using automation and IoT technologies [8]. Android is now the most used mobile operating system in the world. This paper gives a complete knowledge of how to start working on eclipse, develop an application and get it run on emulator [9].

\section{DESIGN OF ORGANIC TERRACE ANDROID APPLICATION}

The objective of the system is to digitalize the procedure of cultivation of crops in terrace through organic approach. This mobile app will be used by garden enthusiasts, health freaks and many urban and sub urban people. The "Organic Terrace" app consists of main page which displays the number of buttons which serve different purpose like guiding information, expert advice link, setting up of notification.

For user interface, Android Studio software will be used. Android studio is the official Integrated Development Environment (IDE) for the Android platform. Based on IntelliJ IDEA software, this is designed specifically for Android development. XML (Extensible Markup Language) will be used for designing the Graphical User Interface (GUI) which will be the front end. XML is used in instantiating layout elements in runtime. Declaration of UI elements is also done using XML. Java is used as platform for app development.

\section{Input}

OrganicTerrace application has information about the procedure to cultivate major vegetable crops. The button press is the only required action from the user to explore things. This selection is taken as input from the user.The user can get an expert advice by clicking the "Reach us" button which opens a mail client. The users can also be notified with some information (watering the plants at right time) during a particular time in the morning.

\section{Process}

The user clicks the button, the activity page with the content from the "strings.xml" and images gets loaded. [10][11]

\section{Output}

The output of the button press is in the form of displays the content page or opensa mail client or displays a notification. [12][13][14][15]

\section{OrganicTerrace App Algorithm}

Step 1: Get the input - a button press from the user.

Step 2: Displaysother activity page after the button press.

Step 3: When pressed "Set a regular reminder", user will get the regular reminder in the form of notification.

Step 4: If the work is done, a user can click on done button in notification which closes the notification.

The figure: 1 below is the Diagrammatic representation (flowchart) of Organic Terrace application and explains how the app actually works.

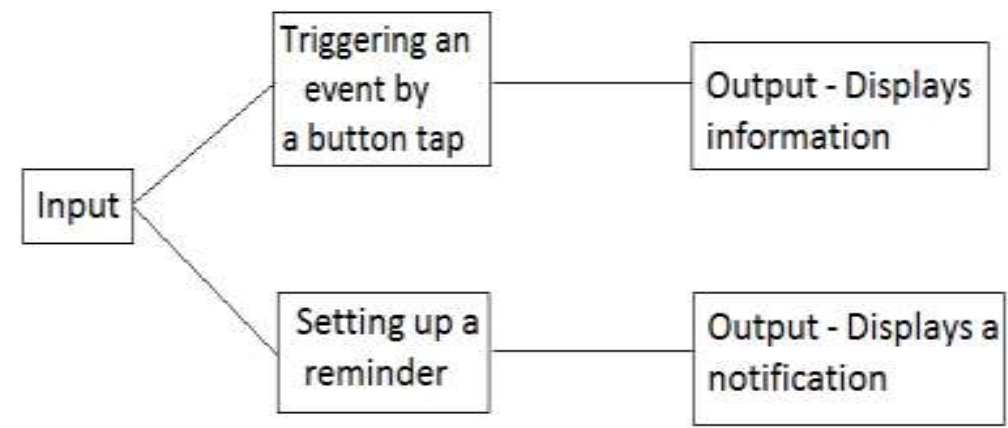

Figure 1: Diagrammatic representation (flowchart) of Organic Terrace app

\section{Experimental Results:}

Organic Terrace app was implemented using android operating system with Android Lollipop 5.1.1 (the largest and most ambitious release for Android)with spanning versions between 5.0 and 5.1.1 as target version which has API 22. Gingerbread 2.3.3 is the minimum operating system requirementfor this application which has API 10.

Figure 2 displaysbuttons, a GUI component like opening many activities, reaching us through app for queries, setting up reminders, etc. Figure 3 and 4 are the sample activity pages. 


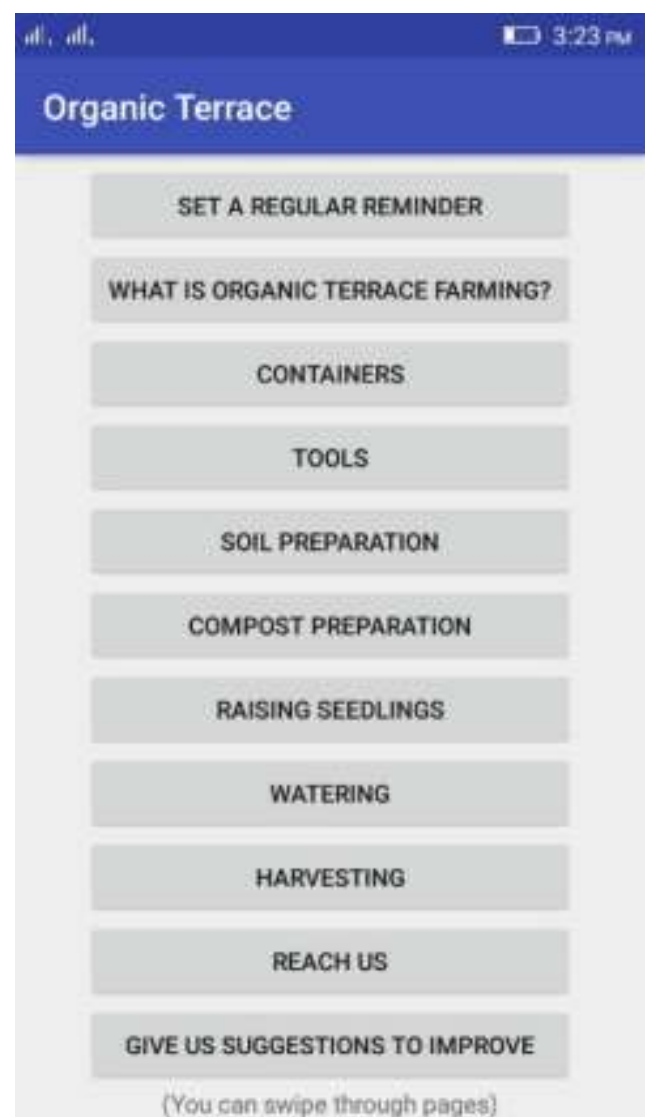

Figure 2: Main page of "Organic terrace" app

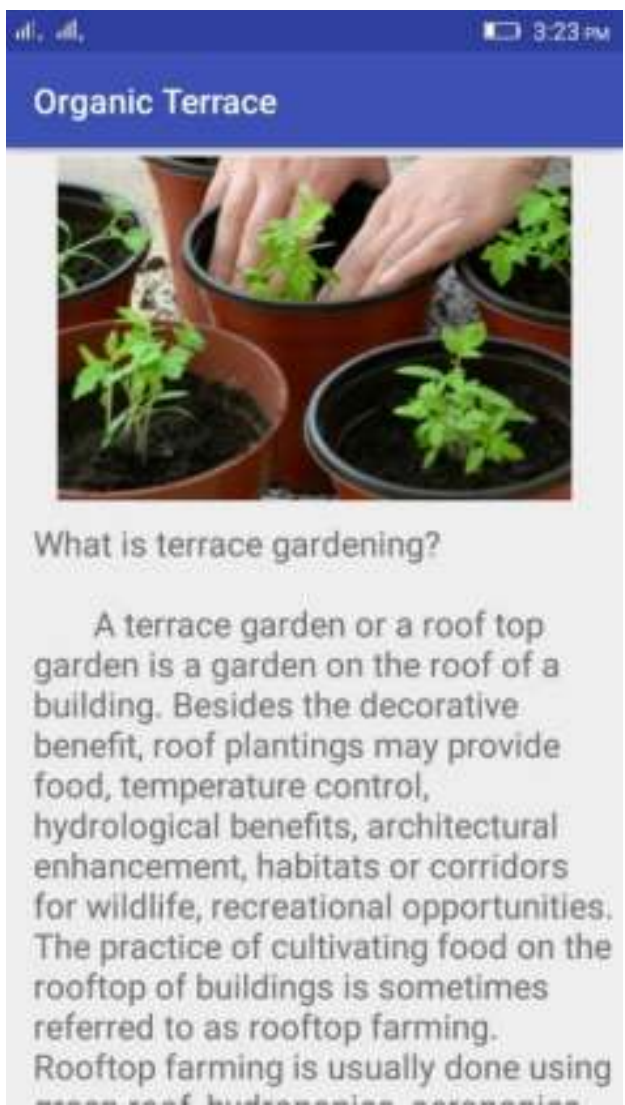

Figure 3: Introduction page of "Organic terrace" app 


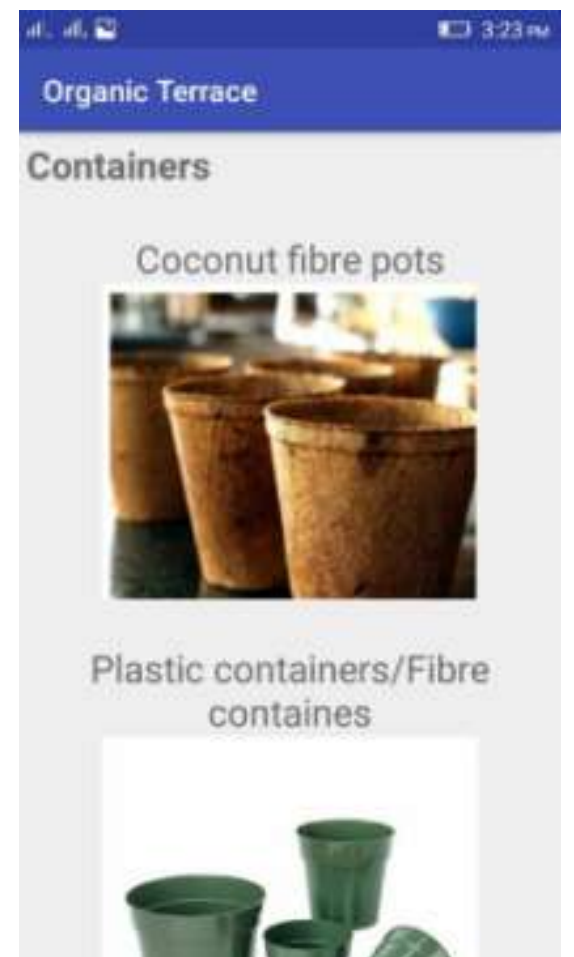

Figure 4: "Containers" page of Organic Terrace app

\section{CONCLUSION AND FUTURE RESEARCH}

OrganicTerraceapp helps in delivering the users with the necessary information and guidelines required for cultivating vegetable crops in the terrace on their own without any external help. Further the app will be very much helpful in leading a very healthy and hygienic life by growing organic crops. Now the application will be able to give an expert advice through mail. But the future scope for this application is to develop a "DISCUSSION FORUM" where the registered users can interact with each other in an effective manner. From this, the users may benefit from each other by sharing the useful information they know.

\section{ACKNOWLEDGMENT}

I wish to thank Dr. M. Kalpana, Assistant Professor, School of Post Graduate Studies, Tamil Nadu Agricultural University, Coimbatore, for her continuous encouragement and guidance.

\section{REFERENCES}

[1]Li Ma, Lei Gu, Jin Wang"Research and Development of Mobile Application for Android -Platform" International Journal of Multimedia and Ubiquitous Engineering Vol.9, No.4 (2014), pp. 187-198

[2]S. Srija, R. Geetha Chanda, S.Lavanya, Dr. M. Kalpana "AgroNutri Android Application" International Journal of Advanced Research in Computer and Communication EngineeringVol. 5, Issue 5, May 2016 ISSN (Online) 2278-1021 ISSN (Print) 23195940

[3] SayaliKamble, Mitali Joshi, Shreya Kale, S. Mahajan "Deployment of Mobile Application for Multiplatform Operating Systems"International Journal of Advanced Research in Computer and Communication Engineering Vol. 4, Issue 4, April 2015 ISSN (Online) $2278-1021$ ISSN (Print) 2319-5940

[4] Dr. M. Kalpana, Dr. D. PeriyarRamasamy, Dr. D. Jaya Kumar“ Development of Fertilizer Apps (F Apps) for well informed Decision Making among the Farmers" International Journal of Advanced Research in Computer and Communication Engineering ISO $3297: 2007$ Certified Vol. 5, Issue 12, December 2016 ISSN (Online) 2278-1021 ISSN (Print) 23195940

[5]Ankit Singh, Abhishek Gupta, Akash Bhosale, SumeetPoddar"Agribot: An Agriculture Robot" International Journal of Advanced Research in Computer and Communication Engineering Vol. 4, Issue 1, January 2015 ISSN (Online): 2278-1021 ISSN (Print): 2319-5940

[6] Aditya Tomar"Flash Alert Notification System using Android" International Journal of Advanced Research in Computer and Communication Engineering ISO 3297:2007 Certified Vol. 5, Issue 9, September 2016 ISSN (Online) 2278-1021 ISSN (Print) 23195940

[7] Monika Chirmade, KomalTayade, Gaurav Sham Bankar, ShounakSugave“Agriculture Supply Chain Management Based Android Application" International Journal of Advanced Research in Computer and Communication Engineering Vol. 4, Issue 4, April 2015 ISSN (Online) 22781021 ISSN (Print) 2319-5940

[8] Nikesh Gondchawar, Dr. R. S. Kawitkar "IoT based Smart Agriculture” International Journal of Advanced Research in Computer and Communication Engineering Vol. 5, Issue 6, June 2016 ISSN (Online) 2278-1021 ISSN (Print) 23195940

[9] Garima Pandey, Diksha Dani “Android Mobile Application Build on Eclipse” International Journal of Scientific and Research Publications, Volume 4, Issue 2, February 2014 ISSN 2250-3153 
[10] http://stackoverflow.com/questions/

[11]http://www.viralandroid.com/

[12]http://www.countryfarm-lifestyles.com/terrace-gardening.html

[13] https://bonnieplants.com/library/

[14] http://geekgardener.in/

[15] http://agritech.tnau.ac.in/

\section{BIOGRAPHIES}

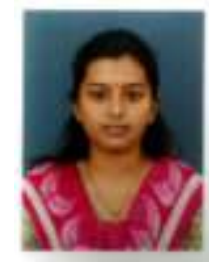

Dhanusha. T has completed her Undergraduate Degree in Agricultural Information Technology from Tamil Nadu Agricultural University. She did her Internship Programme in RAIF, Chennai on Development of Android application.

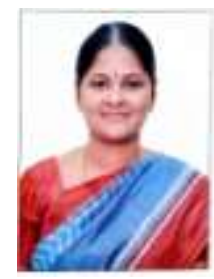

Dr. M. Kalpana obtained her B.Sc Degree (Statistics) in 2001. She is a rank holder in under graduate degree. She obtained her M.C.A degree from Maharaja College for women in 2004 and M.Phil in Computer Science at Madurai Kamaraj University and her Ph.D in Computer Science in Bharathiar University during 2014. She has to her credit three books, 4 papers in National Conference and 2 paper in International Conference, 12 papers in International Journals and two book chapters in IGI Global, U.S.A. She has also coordinated for the training offered by National Horticultural Mission (NHM) to the State Agricultural and Horticultural officers and prepared manuals. She is a Life member of International Association of Engineers (IAENG), International Association of Computer Science and Information Technology (IACSIT) and member of Internet Society (ISOC). She has been awarded Bharat Jyothi Award from India International Friendship Society. 